\title{
Three interrelated problems in reading: A review*
}

\author{
JOHN L. BRADSHAW \\ Monash University, Clayton, Victoria 3168, Australia
}

\begin{abstract}
In this review, three interrelated problems are discussed with respect to reading. The skilled $S$ may recognize words not so much by a serial letter-by-letter analysis, but rather by some sort of interactive process pern itting the extraction of higher order distinctive features. Some semantic information may be available from words beyond the one currently fixated, even though orthographic or phonological information is preconscious or rapidly lost. Finally, the accessing of meaning from the written representation may proceed directly, without any prior or intervening phonological stage. These conclusions are considered within the context of the possibly different aims of the reader at different times, the distinctions between easy and difficult material, and the experienced and the novice reader. Implications for alternative coding systems, such as a syllabary, are discussed in terms of the roles of the phoneme and the syllable as fundamental units in speech perception.
\end{abstract}

The precursors of techniques for recording propositional speech were tally count marks and simple pictorial ideograms for store and account keeping (Diringer, 1968). While the absence of a phonetic component may have made them interpretable to speakers of different dialects and languages (cf. also archaic Chinese ideograms, Jensen, 1970), these records usually only sufficed for concrete objects and simple relationships. Any attempt to extend the system inevitably led to a vast proliferation in the number of symbols to be learned. One attempted solution, at the cost of further ambiguity, has been to represent homophonous items, e.g., sail and sale, by a single pictorial representation, usually of the concrete item (Forrest, 1965). The addition here of a distinguishing mark to show that the homophonous rather than the direct meaning is intended is a step toward phonetic representation. It also poses a further problem should changes develop in the pronunciation of either item or should the usage of either become archaic.

The root forms of words in many of the major language groups are often a single consonant-vowel-consonant (CVC) syllable (Holbrooke, 1910). Several historical attempts have, consequently, been made at developing a syllabic script (e.g., Chadwick, 1972; Diringer, 1968) for representing the sounds of spoken speech. One problem is the large size of the requisite ensemble leading to problems both of memory and visual confusability. The adoption of a third symbolic device, alphabetic script, depends upon an awareness of the motor rather than the acoustic aspects of speech in making a character represent speech at the level of the individual phoneme. In view of the apparent common ancestry of most alphabetic systems (Diringer, 1968; Jensen, 1970), this device may have

*This work was supported by a grant from the Australian R esearch Grants Committee and was completed while the author was visiting Edinburgh University. Address requests for reprints to John L. Bradshaw, Department of Psychology, Monash University, Clayton, Victoria 3168, Australia. been invented once only. With perhaps an original one-to-one relationship between phoneme and character, with about 40 of the former normally being found in any one language (Wise, 1957), the system may seem simple and economical. However, there is dispute as to how natural a unit the phoneme is in speech perception (Liberman, Cooper, Shankweiler, \& Studdert-Kennedy, 1967). Moreover, the original one-to-one correspondence may be largely lost with dialect developments, borrowings, and the evolutionary passage of time (though see Chomsky, 1970). The system does not, however, have the great advantage of permitting a common route for decoding both the written and spoken forms of the language.

In this review, three interrelated problems whici stem from our employment of the alphabetic system are studied. Thus, in reading are words recognized letter by letter, serially, or from higher order distinctive features? How much information, semantic, phonological, or orthographic, is available from each reading fixation? Is a phonological stage essential between whatever form the primary visual analysis may take and the final extraction of meaning? The possible development of an alternative coding system, such as a syllabary, is considered within the context of the possible roles of phonemes and syllables as fundamental units in speech perception.

\section{WORD PERCEPTION: IS THE SINGLE LETTER OR THE LETTER CLUSTER THE BASIC PERCEPTUAL UNIT?}

In reading as experienced adults, we normally made saccades of around 20-msec duration (Gough, 1972), during which perceptual thresholds are raised and no information may be taken in (Volkmann, Schick, \& Riggs, 1968). Fixational pauses of 150 to $300 \mathrm{msec}$ permit the intake of information. We may, therefore, make around six fixations per second (cf. Kolers, 1973), during which time at least as many words will have been 
read. How much information (semantic, orthographic. word length, etc.) is available in each fixation in terms of spaces beyond the point of fixation? Do we internally scan a representation ("icon," Neisser, 1967) up to some limit of resolution? The quantity of information momentarily present in the icon is considerable; that and its duration have been extensively studied by Sperling (1960). The read-in to the store has normally been considered as parallel and the readout as serial, though Sperling (1967) has reported data which he interprets as opposing his earlier hypothesis of strict serial readout. Haber (1970) has obtained evidence for parallel processing in word perception with highly practiced Ss. as have Eriksen and Spencer (1969). Indeed, the question with respect to the reading process itself is to what extent, with normal words with all the serial redundancy of their letters, the latter are scanned serially, one by one, or as clusters. Support for the hypothesis that there is an internal scan comes originally from studies of Ss' report strategies with tachistoscopically exposed random letter strings, which, by their very nature, are themselves likely to encourage serial letter-by-letter processing. Thus, a left visual field (LVF) superiority is reported for bilaterally presented letter strings (Bryden, 1966, 1967; Harcum, 1964; Heron, 1957; Scheerer, 1970); the earlier encountered items are less subject to decay. A right visual field (RVF) superiority is found with unilaterally presented items (Dornbush \& Winnick, 1965; Heron, 1957; Neill, Sampson, \& Gribben, 1971). In this case, direction of scan from the fixation point toward the first element and then onward to subsequent elements is always the same, to the right. With LVF presentations, scan is first to the left, to the initial element of the string, and then to the right, to the subsequent elements. Further support for the internal scanning hypothesis comes from work with Hebrew Ss and material, where reading directions and VF superiorities may be reversed (Forgays, 1953; Mishkin \& Forgays, 1952; Orbach, $1952,1967)$. The same is true with mirror-reversed English material (Harcum \& Finkel, 1963) where, of course, the unfamiliarity of the mode of presentation may again itself emphasize scanning strategies. Kolers (1973), however, found that scanning habits may be so ingrained in the skilled reader that best performance is obtained with a normal left to right scan even with mirror-reversed material. However, it must be remembered that most of the above evidence for the existence of an internal scan comes from artificial material in an artificial experimental situation.

Despite evidence that there may be a reduction in the information gathering capacity of the periphery when the fovea is simultaneously stimulated, over and above the generally lower peripheral acuity (Antes \& Edwards, 1973; Mackworth, 1965), there is also the suggestion that inhibitory processes may operate from the periphery toward the fovea. Thus, with letter strings there are often reports of superior performance for items at the end of the display, away from the fovea (Bouma, 1973: Merikle, Coltheart. \& Lowe. 1971: Shaw \& Weigel, 1973). In fact, Bouma claims that the inward-outward distinction (i.e., fovea to periphery) is more relevant than the initial-final one (Bruner \& O'Dowd, 1958) in word recognition. He rejects scanning as an explanation, as do Merikle et al, in favor of lateral masking or inhibitory effects. Townsend. Taylor, and Brown (1971) take the same view. While Erikson and Rohrbaugh (1970) found that the presence of any nearby contour interferes with the perception of a single letter, Shaw and Weigel (1973), on the other hand, claim that the effect requires adjacent letters, rather than other forms of contour transitions, and reject a neural explanation involving lateral inhibition (cf. Ratliff, 1965). Indeed, they found that interposed bars and blanks in pronounceable nonword letter strings and real words produced the same effects in both kinds of material, enhancing the clarity of the letter on the foveal side of the bar or blank. If this permits a longer duration for processing the letter (because there is no immediately subsequent letter also requiring processing), this would support a serial letter-by-letter processing model. However, one could again argue that the nature of the task and the stimuli employed tended to enhance the serial or letter string aspects, even with the words actually used.

Whether or not, in reading, an internal scan operates within a fixation in a direction and manner parallel to that occurring between fixations, the question remains as to what is the basic perceptual unit in word recognition, between successive instances of which a serial processing scan may possibly take place, overtly or covertly. If we define the perceptual unit as the smallest visual configuration uniquely represented by a property list in long-term memory (LTM), the question can be rephrased as what is the largest fundamental unit within which parallel processing may occur in terms of a mutually facilitative interaction between the components. A consideration of the serial/parallel distinction in word recognition, as Wheeler (1970) points out, shows that processing must be parallel at some point, whether in handling the line fragments that make up the letter, the letters that make up a cluster, the syllable, or the word. Again, even the most radical parallel model demands serial processing beyond some level, whether it is the word, phrase, or sentence. Traditionally, the basic perceptual unit has been the single letter, without any interletter interactions at the perceptual level (Broadbent, 1967; Morton, 1968). Thus, Gough (1972) concluded from his experiments that in normal reading leiters are read out serially from words at a rate of $10-20 \mathrm{msec} / \mathrm{letter}$. He measured pronunciation latencies and word/nonword decision times as a function of number of letters in the word or string. As Brewer (1972) points out, Gough's longer RTs with longer 
stimuli may merely reflect increased time taken for setting up motor programs, whether or not overt speech results. Moreover, the nature of the task and the stimuli could again have tended to enhance the serial or letter string aspects. Herman and McLaughlin (1973) varied the transition probabilities between letters within real, pseudo-, and anagram words in a letter-target detection task. They concluded in favor of a very rapid serial letter-by-letter processing, with each letter reducing the ensemble of possibilities for the next. However, these effects from letter transition probabilities are also entirely compatible with a letter cluster theory of word recognition, with different combinations of letters having different overall frequencies of occurrence, familiarities, and processing speeds.

A related aspect of the problem was studied by Reicher (1969). He made the apparently paradoxical finding that letter recognition is more accurate when the letter is embedded in a word than when presented in isolation. He attempted to control for the possibility of redundancy facilitating recognition of the letter when embedded in the word by, for example, asking $\mathrm{S}$ whether the letter " $\mathrm{d}$ " or " $\mathrm{m}$ " was present in the word which could be either "dove" or "move." Since the Ss did not know until after presentation either the letter or the letter position in the word that would be tested (and the above words can generate many others, such as "dome," "more," etc.), the conclusion from the word-superiority effect was that all four letters in the word were better recognized than was a single letter presented in isolation. As Wheeler (1970) points out, the word-superiority effect is strictly inconsistent both with the serial letter-by-letter model of processing (as, with more letters in a word, performance should be worse) and with a parallel noninteractive model. With the latter, all the letters being simultaneously processed, there should be no difference between the effects for words and single letters. Consequently, Reicher (1969) and Wheeler (1970) conclude that word recognition cannot be analyzed into a set of independent letter recognition processes. There must be some form of mutual interaction or facilitation between the letters of a word, perhaps at the level of the digram or trigram, providing additional features for the recognition of the word over and above those available from the individual component letters. Several potential sources of criticism, however, remain. While Reicher and Wheeler, as well as Smith and Haviland (1972) in a later study, consider that their controls for redundancy in the words were adequate, this is questioned by Massaro (1973) and Thompson and Massaro (1973). The latters' controls, however, may well have forced their Ss into a serial mode of processing-a general problem with all these experiments-hence, artifactually influencing the results against an interactive interpretation. Second, Bjork and Estes (1973) found that, when their Ss knew in advance of a series of trials the letter that they were to detect against a noisy background, there was no overall advantage for letters embedded in words, and any context effects seemed more interpretable in terms of masking than of semantic relations or perception of higher order units. Finally, Mezrich (1973) suggested that phonological encoding of the word stimuli may have accounted for the word-superiority effect, with letter stimuli normally maintained in memory at a physical level during the experimental durations being employed (e.g., Posner, Boies, Eichelmann, \& Taylor, 1969). This would be so unless $S$ is first required to name the single-letter stimuli. A single-letter superiority then appeared at the expense of the words (cf. also Henderson, Coltheart, \& Woodhouse, 1973; Klapp, 1971; Klapp, Anderson, \& Berrian, 1973). Possibly the best controlled study of the word-superiority effect, or, strictly, the superior perception of a letter when embedded in a word as compared with isolated presentation, comes from Johnston and McLelland (1973). They presented letters in isolation, embedded in a word, and embedded in a string of \# symbols, with and without prior information as to position to be tested and with and without pre- and postexposure patterned masking. They confirmed the effect, which was strongest in the masking paradigm; it made no difference whether $S$ had advance knowledge of the position which would be occupied by the critical letter. Since, under the conditions of patterned masking, the identification of a letter embedded in a \# string was no different from when in isolation and in both cases inferior to when embedded in a word, they could not conclude that the patterned mask simply interfered more with the processing of the isolated letter stimulus. However, it is possible that words are processed differently from letters and geometric shapes, the fine detail of the latter perhaps being more subject to disruption than the overall shape of the word. Analogously, speech may not be processed by the same system which is concerned with simple sounds (Liberman et al, 1967; Mattingly, Liberman, Syrdal, \& Halwes, 1971). A related possibility put forward by Johnston and McLelland (1973) is that words are somehow faster processed than letters or more readily transferred to a stable undisturbed state.

Support for the concept of word perception involving a perceptual unit greater than that of the single letter goes back at least as far as Gibson, Pick, Osser, and Hammond (1962). They put forward the idea that readers may operate at the level of letter clusters, with a relatively invariant correlation between spelling and sound. It is, of course, a fact that we often look at the overall shape of a word we have written to decide whether we have spelled it correctly. Moreover, there is considerable evidence (e.g., Liberman et al, 1967) that in speech perception we do not perform a phoneme by phoneme analysis, as they are often difficult to isolate and the process would be far too slow, but operate at the level of the syllable or higher. However, the roles of 
the phoneme and syllable in speech perception will be discussed in more detail below. Travers (1973) found that forced serial processing of letters in a word by serial left-to-right presentation impaired recognition of words more than random letter strings, though he used very long letter exposures of 50 msec. Kolers (1973) similarly found that equally lengthy exposures were required of letters serially presented in a word, much longer than is compatible with our normal reading rate. A criticism which can be levied against both these arguments is that the apparently optimal timing of input of discrete letters making up a word to a buffer store or their readout may not directly relate to optimal circumstances for sequentially processing a group of letters normally encountered simultaneously in reading. Finally, Stanners and Forbach (1973) noted that the initial and final consonant groups in their five-letter items were apparently extracted and encoded as units and used to mark a subset of lexical entries whose size corresponded to the number of words in which those consonant groups appeared. High-frequency consonant groups may mark a larger lexical subset, resulting in slower identification in a word-nonword classification task. Phonological recoding seemed to occur simultaneously as a separate, not as an intervening, stage, permitting the rapid rejection of illegal unpronounceable items.

In conclusion, there is considerable evidence in favor of an interactive model in word perception, with perceptual units larger than the individual letter. However, one must consider the task requirements, its difficulty, the experience and purpose of the reader, whether he is reading for meaning, for the sound (as in poetry), proofreading, or engaging in orthographic search for spelling in a dictionary (Gibson, 1973; Spoehr \& Smith, 1973).

\section{READING: HOW MUCH CAN WE PROCESS FCR MEANING IN A SINGLE FIXATION?}

In the previous section, it was shown that even the most radical parallel model of word perception in reading demands that serial processing commence at some stage, whether it is the word, phrase, or sentence. However, whether or not the letters or syllables of a word are perceived together and whether or not we normally successively fixate word by word, we can still ask whether in each fixation some information is available from the word or words beyond the one currently being fixated. If so, such information may be partial or complete and obtained simultaneously (in parallel) with the processing of the fixated item or obtained subsequently, perhaps as a continuation of a covert internal scan. Indeed, just as an interactive model of word perception suggests that there is possibly some form of mutual facilitation between the letters of a word, so might there be a somewhat analogous process at the level of the word in the accessing or extraction of meaning. Any such interword interactions might oceur at a prephonological or even preconscious level, before $S$ has yet fixated upon the peripherally located item. The possibility of accessing meaning without phonological recoding will, however, be discussed below.

Kolers and Lewis (1972) suggest that peripheral vision probably acts as more than simply a ranging instrument for the fovea and that some content analysis is possible from input presented through several degrees of angle in the visual periphery, while the array forms a single group of letters or a word. Gould (1973) found a linear relationship between fixational duration on a character and its (vertical) separation from a previously fixated character, implying that the amount of information which is encodable about a peripherally located character is proportional to its eccentricity. Both Gould and Chaiken, Corbin, and Volkmann (1967) showed that the useful field of peripheral view is greater horizontally than vertically, again perhaps reflecting our reading habits. However, the information gathering capacity of the periphery is apparently reduced when the fovea is simultaneously occupied (Antes \& Edwards, 1973), a situation effectively leading to a tunneling of vision (Mackworth, 1965). Consequently, in normal reading, Kolers and Lewis (1972) conclude that simultaneous processing of several items or words is not a strategy that the rapid reader could profitably adopt. When their Ss read aloud vertically arranged lists, Bradshaw and Nettleton (1974) found no evidence to suggest that a word lying directly beneath a critical heterophonic homograph (e.g., lead, bow, tear, sow, etc., each of which has two different pronunciations and meanings) would influence the chosen pronunciation of the critical item. For instance, when "bead" lay directly beneath "lead," the latter was no more or less likely to be pronounced in a rhyming fashion with the word beneath it than when the latter was "dead." However, the lists were vertically rather than horizontally arranged, were meant to be read aloud at a rapid rate as discrete words, and the presence or absence of pronunciation or phonological influences need not be considered indicative of how meaning is extracted, especially if the latter can be accessed before, or parallel to, or even in the absence of phonological recoding.

There is, in fact, by now a wealth of evidence that semantic influences can intervene from material unattended by $\mathrm{S}$, of which he is unaware or even unable to report. Mandler and Worden (1973) review the extent to which skilled typists subsequently may be completely unable to recall what they have typed, how the shadower may apparently be unmindful of what he has successfully shadowed, and how the reader of a bedtime story to a child may perform his task to the child's satisfaction without later remembering anything of the content. The material appears either to have been superficially organized during input or to have been rapidly lost from storage. Selective listening experiments 
have demonstrated how material in the attended and unattended channels may interact, leading to the conclusion (cf. Deutsch \& Deutsch, 1963; Norman, 1969) that information may be subjected to more analysis before the level of selection than either Broadbent (1958) or Treisman (1969) envisaged. Lewis (1970) required his Ss to shadow words in the attended message and found that their vocal RTs were longer if semantically related words occurred at the same time in tile unattended, even though the Ss could not afterward remember having heard the latter. Lackner and Garrett (1973) found further evidence that semantic processing may take place for subsequently unreportable material. They presented an ambiguous sentence to the attended ear, with a disambiguating context in the unattended ear. When the Ss paraphrased the ambiguous sentence, their interpretation was influenced by the subsequently unremembered disambiguating context in the unattended channel, suggesting that the latter received at least partial analysis. Moreover, the ambiguous material seemed to be processed for both its possible meanings, even though only one subsequently reached consciousness, a conclusion also reached by Bever, Garrett, and Hurtig (1973). Foss and Jenkins (1973), with ambiguous and nonambiguous sentences, presented half of the former in a disambigiating or biasing context. There were longer RTs for both neutral and biased contexts in the detection of target phonemes when these occurred after an ambiguous word, whether or not S claimed subsequently to be aware of the ambiguity. Again it seemed as if all possible meanings were accessed, and those rejected by the context failed to reach consciousness. Mackay (1973) performed a further series of studies with ambiguous sentences to one ear and disambiguating material to tine otiner, unattended ear. He concluded that sentence processing occurred at two levels. A limited capacity short-term memory (STM) system could simultaneously process both the attended and unattended material, at least at the level of assigning a meaning to each word and analyzing the surface syntax of the sentence. At a deeper long-term memory (LTM) level, the results from the first level of analysis are received. Only here can the underlying structure be analyzed, and only the attended inputs in conscious awareness are so processed. However, he was able to show that lexical ambiguities, for example, homographs such as "palm" (meaning tree or hand), could be resolved at the primary unconscious level of processing in the STM.

In vision, there is similar evidence for the possibility of perception without awareness. Using binocular rivalry, Somekh and Wilding (1973) found that "unperceived" words affected semantically related judgments. In a paradigm very close to the natural reading situation, Willows and MacKinnon (1973) employed Neisser's (1969) selective reading technique to study the effect upon the attended material of peripherally located words, unattended and probably below the level of conscious awareness. A story was read, typed in one color, with irrelevant words typed in a different color between the lines. Although Ss could not remember subsequently the latter material, they gave answers to questions following each passage which seemed to have been influenced by the "unattended" material. Bradshaw, in an unpublished study, tachistoscopically presented a triad of material, a homograph sandwiched between a disambiguating word on one side and a random consonant string on the other. The homograph, flashed across the fixation point, was reported by Ss, who also assigned the perceived meaning, and anything else they had seen presented on either side of this central item. Even when they were unable to report anything about the disambiguating item located immediately adjacent to the ambiguous homograph, they nevertheless tended to assign a meaning to the latter in accord with the unperceived bias word. It seemed that some semantic information had survived the incomplete decoding or rapid forgetting of the adjacent peripheral word, perhaps at a semantic level alone. The fact that the effect was greater when the disambiguating word lay anead of fixation (i.e., in the RVF) suggested the possibility that, in normal reading, material not yet fixated, as well as that already encountered, may serve to reduce the contextual uncertainty of the centrally fixated item. Phonological recoding may take place only for material at or behind fixation.

In conclusion, there seems to be considerable circumstantial evidence that in reading we are capable of extracting some semantic information from words not yet fixated. Whether the rapid reader regularly employs such a strategy can only be answered from some such experiment as where the reading display is linked to the S's fixational eye movements and changes at a semantic and physical level are made during reading in material just beyond the current fixation point.

\section{DIRECT ACCESS VS PHONOLOGICAL RECODING}

Current theories of speech perception emphasize the importance of a motor contribution. It is probable that the acoustic signal, rather than being directly decoded, is analyzed in terms of the sequence of movements that would have been required of the articulators to reproduce that signal (Liberman et al, 1967; Mattingly et al, 1971). Certainly, the distinctive features operating in speech perception are better described in motor (articulatory) rather than purely acoustic terms. Moreover, in this way, a common mechanism can operate both to produce and to receive the speech signal. Analogously, it can be argued that in reading script an intervening stage which includes phonological recoding, i.e., production of an acoustic-articulatory correlate of the written word, would also permit a common mechanism thereafter to handle both visual and auditory 
input. Any phonological stage need not, of course, include overt articulation, though under load or stress movements of the articulators may be detectable (Hardyck \& Petrinovitch, 1970). Indeed, since reading can be up to 10 times faster than speaking (Landauer, 1962; Kolers, 1973), phonological recoding would need to operate at an extremely abstract level, even taking into account the serial redundancy of written material, which might permit very selective sampling. Morton's logogen theory (1969) claims that meaning is accessed through the activation of units which include the previous sensory and motor associations of a word, whenever and however it is encountered. Children, certainly, when learning to read, and adults, too, when they encounter difficult or unfamiliar material, will "sound out" the material letter by letter or syllable by syllable. Do experienced adults, when reading for meaning and not, as in poetry, attending to the sound of the passage, rapidly reproduce the phonological structure when addressing the internal lexicon? This question (see Smith, 1971) is still relevant, whether a word is processed letter by letter, in terms of letter clusters, or the syllable of some larger unit, though intuitively phonological recoding may seem more likely the smaller the perceptual unit in word recognition.

\section{Arguments Supporting Mediated Access, Phonological Recoding}

(1) As mentioned above, the strongest support comes from the resulting availability of a common decoding mechanism for verbal material in both visual and auditory modalities. Its importance is implicit in the argument of Chomsky (1970) and Chomsky and Halle (1968) that conventional English orthography in its essentials is a near optimal system for representing the spoken language in that the written symbols correspond fairly closely to the segments of the highly abstract lexical representation. Gough (1972) likewise claims that we map characters on to a string of systematic phonemes, abstract entities like those of Chomsky, which are prior to the sounds of language and which relate to them only by a complex system of phonological rules. While this may indeed be one of the ways whereby we process the written word, it must be remembered, as Brewer (1972) points out, that any evidence showing direct processing of words without a phonological transformation is incompatible with the exclusive operation of such a mechanism. That such a mechanism may be available cannot, therefore, constitute proof that it is always or even sometimes utilized.

(2) With difficult or unfamiliar material, or with inexperienced readers, overt "sounding out" is a common strategy. Hardyck and Petrinovitch (1970) found that the suppression of minimal lip movements interfered with the reading of difficult rather than of easy material. One can still conceive of some covert, perhaps abstract, and necessarily ultrarapid form persisting even for easy material, rapidly scanned. However, the rapid reading rates which are attainable (Landauer, 1962; Kolers, 1973) do seem to make any such articulatory component, however covert or abstract, appear somewhat unlikely or unnecessary. In their review, Meyer, Schvaneveldt, and Ruddy (1974a) consider the possible role of speech-muscle activity during reading and the phenomenological presence of an "inner voice." Both, however, could merely be epiphenomena.

(3) The two sensory disabilities which may be involved in problems of communication, deafness and blindness, in both cases permit an alternative coding system to be employed in the surviving modality which is of a phonological nature (Braille and sign language for the deaf). As might therefore be expected, given a sensory deficit from birth, deafness may prove more disruptive in learning to read characters than blindness. With the latter, the grapheme-phoneme link is still available, if through another (tactile) modality. Again, however, one must remember the distinction between beginner's strategies in the acquisition of a new unfamiliar skill, particularly where, as here, there may be the added presence of sensory deficits, and possible alternative strategies available to those already skillful with unimpaired senses.

(4) The working memory or short-term store (STM) appears to employ acoustic-articulatory coding (Conrad, 1964). It is likely to be important in enabling the reader to hold enough sequential information together to permit the extraction of syntactic, grammatical, and maybe semantic relationships. Nevertheless, many of the classic experiments demonstrating the importance in STM of acoustic-articulatory confusions, rather than visual ones, bear little relationship to the typical reading situation in terms of nature and amount of material presented, retention interval, and recall requirements.

(5) Much the same criticism applies to the following two related findings, which, if extended to the reading situation, would seem to favor an intervening phonological stage. An acoustically confusable target letter (e.g., t) in a list composed of letters such as b, c, d, $\mathrm{g}, \mathrm{p}$, and $\mathrm{v}$ leads to slower search times than where the target is not so confusable, e.g., f or k (Krueger, 1970). Likewise, it is easier to detect the omission of pronounced letters in proofreading than unpronounced letters (e.g., a terminal e as in "some," Corcoran \& Weening, 1968).

(6) The experimental paradigm may be different, but a similar criticism can again be made to the following argument. Pronounceable nonwords sounding like words (e.g., VURSE, HIRT) are more difficult to classify as nonwords, giving longer RTs and more errors, than are pronounceable nonwords that do not even sound like words, e.g., GLITE, SOYD (Rubenstein, Lewis, \& Rubenstein, 1971). Unpronounceable letter strings are 
the quickest and easiest of all to reject (Stanners \& Forbach, 1973). However, pronounceable nonwords may merely look more like English words and unpronounceable letter strings least like English words, leading to a confounding of visual and phonological factors. Indeed, the use of single words in stimulus presentation, some of which Ss would come to expect and recognize as homophones, could very well encourage prior phonological recoding. Moreover, as will be seen in the next section. Forster and Chambers (1973), in an analoguus experiment, obtained evidence that naming and categorization are independent events, taking place after the completion of lexical search, with lexical access occurring before any phonological information is available

(7) In the Stroop experiment, color words are presented in dyes which may be the same as or different from those named by the words which they constitute. Naming of the dyes is subjected to interference when there is disparity and is facilitated when, for example, the word "green" is written in a green dye (for review, see Dyer, 1973). If this is due simply to automatic phonological recoding, it is certainly very difficult to suppress (Dalrymple-Alford, 1972). Since, however, single-word stimuli are typically presented, the required overt naming (of the dye) may lead to a problem in response selection, $\mathrm{S}$ tending to name tinat part of sucin a stimulus which is in fact more commonly named (i.e., the word itself rather than its color).

(8) Vocal initiation latencies for the naming aloud of single words or one or more syllable numbers (e.g., 1, 7, $12,77)$ are often found to be a function of the number of syllables when number of letters or symbols is controlled (Eriksen, Pollack, \& Montague, 1970; Klapp, 1971). If the initiation latency is a function of the recognition time, then some phonological recoding of the visually presented symbol seems implied. Alternatively, the initiation latency may merely reflect the time taken to program the required motor sequence for the production of a sort of ballistiform articulatory chunk. This would have no relevance whatsoever to the perceptual or recognition functions but would relate to response initiation alone. In an attempt to resolve this question, Klapp (1971) required his Ss to perform a "same-different" manual RT task, i.e., perception without articulation. While latencies did tend to increase with number of syllables, the effect was different for the two kinds of judgment (same, different). In 1973 Klapp et al again found that only the more difficult responses "different" were associated with longer RTs to picture-name pairs where the latter had more syllables, perhaps implying that the syllable length effect is a function of difficulty, just as implicit speech is more often detectable in the myographic records of Ss reading difficult material (Hardyck \& Petrinovitch, 1970). When names alone were presented for manual categorization into animal/nonanimal groups, the RTs showed no syllable length effect and, hence, no evidence of implicit speecin. The effect was restored when vocal initiation latencies were measured in naming pictures. They concluded that the syllable length effect is due to tine setting up of articulatory programs and that implicit and overt sueech is maybe important in learning to read and with difficult material or during reinearsal, but that a syllable length effect, where present, does not support mediated access in the reading of easy or familiar material. Indeed, Henderson, Coltheart, and Woodinouse (1973) failed to find any syllable length effect at all and ascribed the original findings to a confounding of syllable length with number of letters. Spoenr and Smith (1973) did obtain the effect with tachistoscopic word recognition thresholds but put it down to a parsing of the words at the visual level into segments akin to syllables, each acting as a single perceptual unit, with more segments the longer the word.

\section{Arguments Supporting the Possibility of Direct Access Without a Necessary and Prior Phonological Stage}

The strongest theoretical argument in favor of mediated access stems, by analogy with speech perception itself, from the availability of a common decoding mechanism, despite the fact that the rapid reading rates which are attainable would require a higily abstract phonological mechanism. However, the strongest experimental evidence, the syllable length effect with vocal initiation latencies, was in the end shown not to be supportive, certainly with easy, familiar material. The following arguments generally tend to favor the possibility of direct access.

(1) With heterographic homophones (e.g., SHOOT, CHUTE; HEARD, HERD; etc), the sinape of the word seems important, not its sound, in disambiguating the meaning. Such pairs are not normally read as ambiguous in or out of a sentence context, despite sharing the same phonology and pronunciation.

Indeed, if a phonological stage always intervened, we should be able to apprehend immediately the following sentence: EYE DO KNOT NO Y AWL YEW GNEISS BUOYS SO SEW SLOE. In fact, the sentence looks extremely unfamiliar, even though it is constructed from otherwise valid real words (homophones), and takes a long time to decipher. Bower (1970) found tinat reading was slowed when letters were substituted which changed not the sound but only the appearance of words. However, he failed to use real words in his substitutions. Baron (1973) found that Ss can classify as nonsense phrases which sound sensible ("tie the NOT") as quickly as phrases which do not even sound right. However, with difficult material he did tend to get more errors, wilen in fact phonological recoding might anyway nave been anticipated. He also found that there were fewer errors and Ss were faster in deciding whetiner tine phrases sounded right, regardless of how they looked, when given phrases which looked and sounded right.

(2) With Geterophonic homographs (e.g., LEAD, 
TEAR, WOUND, etc.), it is often necessary to know the meaning before the word can be correctly pronounced, e.g., "The TEAR oil the face of the mummy," The first LEAD in the mine," A ROW is nice sometimes." Nevertheless, the work discussed earlier of Lackner and Garrett (1973), Bever et al (1973), and Foss and Jenkins (1973) with ambiguous material suggests that the homograph words would have both possible meanings accessed, even though only the one fitting the context might actually reach consciousness. Consequently, there might well be an increase in pronunciation latencies witi such words. This would not, therefore, necessarily be incompatible with a phonological stage.

(3) We readily learn to process, recognize, and handle "unpronounceable" mathematical and chemical formulae in groups or chunks. The Chinese cope not unsuccessfully with the reduced phonological component in their script. Moreover, we often look at the overall shape or pattern of a word in deciding whether or not we have correctly spelled it-it "looks" right or wrong. Indeed, the correct orthographic form of a word often looks completely idiosyncratic and characteristic. This does not necessarily mean that we always need to recognize directly, from their shape, all the tens of thousands of words that we encounter. We may, however, often be able to do so with a more limited number of the high-frequency words which make up the bulk of our reading. Rarer words, when encountered. are often deliberately spelled out.

(4) Steinheiser and Burrows (1973) presented monosyllabic and nonsense words, measuring their Ss' classificatory RTs. They required a positive response (1) if there was a target present of any final consonant (phonological analysis), (2) if the item was a real word (lexical analysis), or (3) if either of the above were true (combined phonological and lexical analysis). They found that the values for the first two cases were equal but that those for the third were longer, implying a serial or overlapping process, and that the meaning could be accessed without phonological recoding, and in the same length of time as the latter, if necessary. Similarly, Stanners and Forbach (1973) observed that in a word/nonword discrimination task, phonological recoding may occur simultaneously as a separate, not as an intervening stage, permitting the rapid rejection of illegal unpronounceable items.

(5) Bradshaw and Nettleton (1974) presented their Ss with heterophonic pairs (words closely similar in spelling but not in pronunciation) such as MOWN-DOWN, QUART-PART, HORSE-WORSE. Times for initiating as well as completing the vocalization of the pair, the first alone, or the second alone were measured. Overt articulation of the first was found to be required for there to be any delay in initiating vocalization of the - second; observation or storage of the first was insufficient. This indicated that articulatory interference, as in the above heterophone effect, depended on establishing a pronunciation set with actual speech and that a word could be recognized, identified, or stored without such phonological recoding. On the other hand, Meyer, Schvaneveldt, and Ruddy (1974a) manipulated graphemic and phonemic relations within various pairs of letter strings in a somewhat similar manner to that of Bradshaw and Nettleton (1974). In classifying the pairs as words or nonwords, RTs and error rates proved relatively small for word pairs (e.g., BRIBE-TRIBE) which were both graphemically and phonemically similar. Graphemic similarity alone inhibited performance on the other word pairs such as COUCH-TOUCH (i.e., ineterophone pairs, in the terminology of Bradshaw and Nettleton). Meyer et al conclude that phonological representations must play a significant role in visual word recognition and that there is a dependence between successive phonemic encoding operations. It is possible that the reason for the discrepancy between the findings of these two studies stems from the different demands placed on the Ss. In the Meyer study, the Ss are required to do something not normally performed in the typical reading situation-decide whether or not a pair of words are real. Readers of normal text do not very often have to make such decisions and, when they do, because of typographical errors or word rarity, it would be expected that they should go back for a phonological retake. In the Bradshaw study, the task is closer to that of normal reading, i.e., observe and store the first word, articulate the second. It was only when $S$ actually articulated the first word before the second (in the heterophone pair) that interference or inhibition of the second took place.

Indeed, in a subsequent study employing similar material to their earlier one, Meyer, Schvaneveldt, and Ruddy (1974b) conclude that their data are compatible with a dual model of lexical access, direct and indirect, with both processes perhaps occurring simultaneously.

(6) Circumstantially, the strongest evidence that reading can take place without phonological recoding would stem from a demonstration that the deaf and dumb, who have never learned to speak, can still be taught to read. The data for this are at best controversial. Gibson, Shurcliff, and Yonas (1970), working with deaf Ss, claimed that reading can take place without a phonological stage. Indeed, Conrad (1972) asserts that "speech-like sounds" actually obstruct rather than mediate communication with "profoundly deaf" children. He concludes that reading is certainly possible, though not necessarily optimal, in the complete absence of any phonology and that in this case an exceptional visual memory may be an advantage. However, for the argument as a whole to be valid, the readers would have to be complete deaf-mutes. Such people are notoriously difficult to train to read, a fact that is more compatible with the theory of mediated phonological access.

(7) Perhaps one of the strongest pieces of experimental evidence in favor of direct access comes 
from a recent study of Forster and Chambers (1973). They aimed to determine whether in pronouncing a word a lexical access is first performed or whether grapheme-phoneme correspondence rules are instead applied, a closely related question to that of direct or mediated access in reading. They compared word-naming times and lexical decision times (word/nonword classification) for words and equally pronounceable nonwords. They argued that, if grapheme-phoneme correspondence rules are always used to determine pronunciation, naming times should be the same for both types of material. If a lexical access is always involved, words (especially high-frequency words) should be faster, as long as the operation of lexical access is faster than the application of grapheme-phoneme correspondence rules. If naming occurs after lexical access, then, for words, naming times and lexical decision times should be correlated, involving as they do the common element of lexical access time. For nonwords, as there is no common element, there should be no correlation, naming time being a function of the time taken to apply grapheme-phoneme correspondence rules and lexical decision time being a function of the time taken to discover that there is no lexical entry for the letter string. They found that naming time for words, especially high-frequency words, was shorter than for nonwords and that there was a positive correlation between naming and lexical decision times for words but not for nonwords. They concluded that naming and categorization are independent events taking place after the completion of a lexical search, lexical access occurring before the availability of any phonological information, with the latter being determined by the former rather than by the application of grapheme-phoneme correspondence rules.

In conclusion, the skilled reader of relatively simple material seems capable of extracting much of the semantic content of a passage, without going through a necessary prior stage of phonological recoding. Whether he always does so may depend upon the relative familiarity of the material and what he wishes to do witi it. While written language is ultimately derived from the spoken form, both should perhaps be regarded as at least partly independent abstract systems, two different means for the skilled practitioner for representing relationships between objects and concepts which have more or less similarity in their arrangements. The skilled reader may treat words as symbols providing clues without always giving them as complete an analysis or processing as he is capable of giving them. As Kolers (1970) points out, when a policeman holds up his hand to stop, we treat this signal as such without necessarily determining which hand was used or whether or not it was gloved.

\section{SUMMARY}

The historical development of recording systems took a radical new turn with the ability to represent the spoken word rather than merely portraying pictographically objects or events. Furthermore, the invention of an alphabetic, as opposed to a syllabic script, reduced the ensemble of characters to an easily learned number and originally permitted great flexibility, though perhaps at the expense of some artificiality. Thus, children learning to read do not always immediately comprehend the relationship between a symbol and the fairly abstract concept of an isolated phoneme. Moreover, it now appears that the skilled reader may not necessarily utilize directly this alphabetic code but may in a sense historically regress by sometimes learning to recognize the words directly by their overall shape rather than by processing each letter serially and separately. It is, therefore, somewinat paradoxical that the alphabetic system, whose initial virtue might have been seen as a means to the acquisition of reading skill, should be only partially successful in that area as a result of its own relative abstractness and that the skilled reader might at least part of the time bypass it and process the word as a more or less unitary pattern. Furthermore, he might even be capable of directly apprehending meaning without a necessary prior stage of phonological recoding. This again suggests some redundancy in the alphabetic system, at least for the experienced reader with familiar material. This behavior is not, of course, uncharacteristic of the central nervous system with its tendency at the perceptual, cognitive, and motor levels to integrate existing patterns of activity into hierarchically superior groupings as experience continues (Lashley, 1958).

In speech perception, where the more or less continuous signal is not reliably segmented into language-sized units, there is increasing evidence that the syllable may be a rather fundamental unit. Thus, approximately the same time constant $(180 \mathrm{msec})$ appears in three contexts: the median duration of spoken syllables (Huggins, 1964), the most disruptive delay under delayed auditory feedback (DAF, Robinson, 1972), and the interaural switching rate which leads to the poorest understanding of a message (Cherry, 1953; Cherry \& Taylor, 1954; Rupf, Hughes, \& House, 1971; Schubert \& Parker, 1954). Moreover, Huggins (1964) found that the interaural switching rates producing the worst performance were greater for speeded speech by just the speedup factor. Robinson (1972) found that the DAF interval maximally disruptive to speech moves along as an inverse linear function of speech rate, if the latter can be made to speed up or slow down by external visual pacing. Cole (1973) considers the syllable to be the basic structural unit for grouping phonemes at both the perceptual and articulatory levels by providing a prosodic framework or sequencing of points of stress. Thus, the effects of DAF persist even with grossly filtered or distorted speech (Bradshaw, Nettleton, \& Geffen, 1972). Massaro (1974) also concludes in favor of the syllable as the fundamental unit of speech perception, even though neither the syllable nor the 
phoneme can exist without cach otler. His evidence comes from attempting to measure the duration of the preperceptual auditory image as an estimate of the minimum-duration perceptual unit in speech. He found that recognition performance of stimuli improved when a mask was delayed up to $250 \mathrm{msec}$ (roughly the duration of a syllable) after presentation. However, it could be argued that, as his speech stimuli were themselves syllable-like, the obtained measure could be an artifact of the stimuli he employed.

Other studies involving RT measures for specified targets in lists have suggested that the internal lexicon is represented in terms of a syllabary (Savin \& Bever, 1970). The latter found slower phoneme detections than when the target was a syllable and claimed that phonemes are only identified after completion of the analysis of words, syllables, etc. of which they are part and that this analysis does not normally take into account the internal structure of the syllable. They concluded, however, that phonemes must have some independent, if abstract, existence interrelating between sensory input and articulatory output, in view of the existence of rhyme and alliteration in nonliterate poetry, the natural occurrence of segmental spoonerisms, and the sound shifts which seem to occur at phonemic levels in the history of language evolution. Steinheiser and Burrows (1973) similarly concluded that phoneme monitoring is not normally a component of word monitoring, that phonemes are not primary units of speech, and that the obtaining of phonemic and lexical information may be two quite independent operations, with the latter possibly occurring during the former but not necessarily dependent upon it. They, too, favored the syllable as a unit of both lexical and phonemic analysis (where the latter should be required) and found that syllable identifications were faster than lexical analyses involving word/nonword decisions. Several studies (Foss \& Swinney, 1973; McNeill \& Lindig, 1973; Warren, 1971) have found fastest target detections for words, followed by syllables, with target phonemes the slowest of all to be detected.

Does this mean that syllables too should be viewed as abstract entities?

The extreme situation comes with the finding of Bever, Savin, and Hurtig (see Bever, 1970) that RTs are fastest when Ss know the entire sentence as a target. McNeill and Lindig (1973), however, suggest that such findings are artifacts of the experimental design in that there is generally a mismatch between the linguistic level of the target and the search (list) material and that minimum RTs will always occur (as they found) when the linguistic levels of the two sets of material are the same. They comment upon the phenomenon of "linguistic transparency," whereby in listening to speech we are normally unaware of the (necessarily "perceived") underlying phonological and grammatical structures. When the target and the search list are on different levels, $\mathbf{S}$ must spend time dividing his attention between two mutially transparent objects. Both MeNeill and Lindig (1973) and Foss and Swinncy (1973) observe that, as a result, the target-monitoring task does not tap into the comprehension process at a level corresponding to immediate perception. What is perceptually real is what we normally attend to, which in normal speech will tend to be meaning rather than syllables, phonemes, or even words. While Vitz and Winkler (1973) still tend to favor the syllable as a fundamental unit in speech perception, they too suggest that the early stages in processing are rapid, automatic, and unconscious, with consciousness only supervening at the termination of these processes and the point of termination possibly being amenable to experimental manipulation by set or instruction, but otherwise being when meaning is extracted. Thus, the hearer will usually consciously identify meanings first and will only go to the normally transparent lower levels by a process of successive fractionating. Indeed, in a visual list-search task (Bradshaw \& Ferguson, 1969), it was found that Ss apparently were unable to avoid processing for meaning, even when the target was phonologically defined. Thus, list-search times were faster with lists containing items grouped into classificatory sets, as compared with when the items were randomly rearranged and intermingled. Moreover, the increase in search time was exactly the same whether the target was semantically defined (e.g., "look for any animal name") or directly given (e.g., "look for the word HORSE").

In conclusion, therefore, to search for a fundamental unit in speech perception may be to search for an elusive entity. Both syllables and phonemes appear to be useful abstract concepts and, in fact, to interrelate closely with each other. If meaning is extracted through such transparent entities, this in itself is compatible with the suggestion in the earlier part of this review, that semantic information but not necessarily phonological or graphological information may be available from words beyond fixation. It also gives further support to the possibility of direct lexical access in reading, without the necessity always for phonological recoding.

Consequently, there would seem to be little advantage in constructing, in place of the alphabet, a syllabary. The problems encountered with historical syllabaries such as the Cretan (Diringer, 1968) would remain. A very large number of characters would be needed and representation of consonantal words such as "strength" would be difficult. The only ultimate advantage of any sort of developed syllabary might be shorter words, perhaps more readily permitting the rapid "parallel" extraction of semantic information from points beyond fixation. However, such an increase in available information might itself result in longer fixations, the only savings being in number of saccades. Indeed, if phonological recoding is at all important, if Chomsky's (1970) view is accepted that our orthography is a near-optimal representation of the segments of our highly abstract lexical system, being robust enough to 
cope with dialect differences and language evolution as it covers the commonalities and ignores minor irrelevant differences of detail which are covered by the automatic processes of spoken language, then we should certainly adhere to the alphabetic system. As Venezky (1970) points out, while we normally obtain the correct pronunciation from the or thography by application of a small number of rules, the reverse is not necessarily true. There are many ways of writing the sound $/ \mathrm{j} /$, e.g., g, $\mathrm{j}$, $\mathrm{dg}$, and even $\mathrm{d}$. Consequently, the recoding problems differ depending upon whether you are reading or writing, the former perhaps being initially easier. Thus, any attempt at improving our script might best concentrate on expanding the alphabet so that each phoneme has a symbol, eliminating redundancies and redesigning the characters so that there is minimal interitem visual confusability and, in consequence, a maximum of higher order distinctive features to facilitate direct word recognition wherever this might be possible.

\section{REFERENCES}

Antes, J. R., \& Edwards, D. C. Information processing in tine visual periphery. Bulletin of the Psychonomic Society, 1973, $1,351-353$

Baron, J. Phonemic stage not necessary for reading. Quarterly Journal of Experimental Psychology, 1973, 25, 241-246.

Bever, T. G. The influence of speech performance on linguistic structure. In G. B. Flores d'Arcais and W. J. M. Levelt (Eds.), Advances in psycholinguistics. Amsterdam: North Holland, 1970 .

Bever, T. G., Garrett, M. E., \& Hurtig, R. The interaction of perceptual processes and ambiguous sentences. Memory \& Cognition, 1973, 1, 277-286.

Bjork, E. L., \& Estes, W. K. Letter identification in relation to linguistic context and masking conditions. Memory \& Cognition, 1973, 1, 217-223.

Bower, T. G. R. R eading by eye. In H. Levin and J. P. Williams (Eds.), Basic studies on reading. New York: Basic Books, 1970 .

Bouma, $H$. Visual interference in the parafoveal recognition of initial and final letters of words. Vision Research, 1973,13, 767-782.

Bradshaw, J . L., \& Ferguson, B. Effects of semantic, acoustic and frequency factors on list searching. Nature, 1969,124 , 726-728.

Bradshaw, J. L., \& Nettleton, N. C. Articulatory interference and the MOWN-DOWN heterophone effect. Journal of Experimental Psychology, 1974, 102, 88-94.

Bradshaw, J. L. Nettleton, N. C., \& Geffen, G. Ear asymmetry and delayed auditory feedback: Effects of task requirements and competitive stimulation. Journal of Experimental Psychology, 1972, 94, 269-275.

Brewer, W. F. Is reading a letter-by-letter process? In $J, F$ Kavanagh and I. G. Mattingly (Eds.), Language by ear and by eye: The relationships between speech and reading. Cambridge: M.I.T. Press, 1972.

Broadbent, D. E. Perception and communication. London: Pergamon, 1958 .

Broadbent, D. E. Word frequency effect and response bias Psychological Review, 1967, 74, 1-15.

Bruner, J. S., \& O'Dowd, D. A note on the informativeness of parts of words. Language \& Speech, 1958, 1, 98-101.

Bryden, M. P. Accuracy and order of report in tachistoscopic recognition. Canadian Journal of Psychology, 1966, 20, 262-272.

Bryden, M. P. A model for the sequential organization of behavior. Canadian Journal of Psychology, 1967, 21, 37-56. Chadwick, J. Life in Mycenaean Greece. Scientific American, $1972,227,36-44$

Chaiken, J. D., Corbin, H. H., \& Volkmann, J. Mapping a field of short-time visual search. Science, 1967, 138, 1327-1328.

Cherry, E. C. Some experiments on the recognition of speech, with one and with two ears. Journal of the Acoustical Society of America, 1953, 25, 975-979.
Cherry, E. C., \& Taylor, W. K. Some further experiments upon the recognition of speech with one and with two ears. Journal of the Acoustical Society of America, 1953, 25, 554-559.

Chomsky, N. Phonology and reading. In $\mathrm{H}$. Levin and J. P. Williams (Eds.), Basic studies on reading. New York: Basic Books, 1970.

Chomsky, N., \& Halle, M. The sound pattern of English. New York: Harper \& Row, 1968.

Cole, R. A. Perceiving syllables and remembering phonemes. Journal of Speech \& Hearing Research, 1973, 16, 37.47.

Conrad, R. Acoustic confusions in immediate memory. British Journal of Psychology, 1964, 55, 75-84.

Conrad, $R$. Speech and reading. In J. F. Kavanagh and I. G. Mattingly (Eds.), Language by ear and by eye: The relationships between syeech and reading. Cambridge: M.I.T. Press, 1972.

Corcoran, D. W. J., \& Weening, D. L. Acoustic factors in visual search. Quarterly Journal of Experimental Psychology, 1968, 20, 83-85.

Datrymple-Alford, F. C. Sound similarity and color-word interference in the Stroop task. Psychonomic Science, 1972. $28,209-210$.

Deutsch, J. A., \& Deutsch, D. Attention: Some theoretical considerations. Psychological R eview, 1963, 70, 80-90.

Diringer, D. The alphabet: $A$ key to the history of mankind. 3rd ed. London: Hutchinson, 1968.

Dornbush, R. C., \& Winnick, W. A. Right-left differences in the tachistoscopic identification of paralogs as a function of order of approximation to English letter sequences. Perceptual \& Motor Skills, $1965,20,1222-1224$.

Dyer, F. N. The Stroop phenomenon and its use in the study of perceptual, cognitive, and response processes. Memory \& Cognition, 1973, 1, 106-120.

Eriksen, C. W., Pollack, M. D., \& Montague, W. E. Implicit speech: Mechanism in perceptual encoding. Journal of Experimental Psychology, 1970, 84, 502-507.

Eriksen, C. W., \& Rohrbough, J. W. Some factors determining efficiency of selective attention. American Journal of Psychology, 1970, 83, 330-342.

Eriksen, C. W., \& Spencer, T. Rate of information processing in visual perception: Some results and methodological considerations. Journal of Experimental Psychology Monograph, 1969, 79(No. 2, Part 2).

Forgays, D. G. The development of a differential word recognition. Journal of Experimental Psychology, 1953, 45, 165-168.

Forrest, R. A. D. The Chinese language. London: Faber, 1965.

Forster, K. I., \& Chambers, S. M. Lexical access and naming time. Journal of Verbal Learning \& Verbal Behavior, 1973 , $12,627-635$.

Foss, D. J., \& Jenkins, C. M. Some effects of context on the comprehension of ambiguous sentences. Journal of Verbal Learning \& Verbal Behavior, 1973, 12, 577-589.

Foss, D. J., \& Swinney, D. A. On the psychological reality of the phoneme: Perception, identification and consciousness. Journal of Verbal Learning \& Verbal Behavior, 1973, 12, 246-257.

Gibson, E. J. Some reflections on the reading process. Address to Edinburgh University School of Epistemics, 1973.

Gibson, E. J., Pick, A. D., Osser, H., \& Hamm ond, M. The role of grapheme-phoneme correspondence in the perception of words. American Journal of Psychology, 1962, 75, 554-570.

Gibson, E. J., Shurcliff, A., \& Yonas, A. Utilization of spelling patterns by deaf and hearing subjects. In $H$. Levin and J. $P$. Williams (Eds.), Basic studies on reading. New York: Basic Books, 1970

Gough, D. B. One second of reading. In J. F. Kavanagh and I. G Mattingly (Eds.), Language by ear and by eye: The relationships between speech and reading. Cambridge: M.I.T. Press, 1972

Gould, J. D. Eye movements during visual search and $m$ emory search. Journal of Experimental Psychology, 1973, 98, 184-195.

Haber, R. N. How we remember what we see. Scientific American, 1970, 222, 104-112.

Harcum, E. R. Effects of symmetry on the perception of tachistoscopic patterns. American Journal of Psychology, $1964,77,600-606$.

Harcum, E. R., \& Finkel, M. E. Explanation of Mishkin and Forgays' result as a directional reading conflict. Canadian Journal of Psychology, 1963, 17, 224-234.

Hardyck, C. D., \& Petrinovitch, L. R. Subvocal speecin and comprehension level as a function of the difficulty level of reading material. Journal of Verbal Learning \& Verbal Behavior, 1970, 9, 647-652.

Henderson, L., Coltheart, M., \& Woodhouse, D. Failure to find a syllabic effect in number naming. Memory \& Cognition, 1973, 1, 304-306.

Herman, D. J., \& McLaughlin, J. P. Language habits and detection in very short-term memory. Perception \& 
Psychophysics, $1973,14,483-486$

Heron, W. Perception as a function of retinal locus and attention. American Journal of Psychology, 1957, 70, 38-48.

Holbrooke, G. O. Aryan word building. New York: Knickerbocker, 1910.

Huggins, A. W. F. Distortion of the temporal pattern of speech Interruption and alternation. Journal of the Acoustical Society of America, 1964, 36, 1055-1064.

Jensen, H. Sign, symbol and script: An account of man's efforts to write. London: Allen \& Unwin, 1970.

Johnston, J. C., \& McLelland, J. L. Visual factors in word perception. Perception \& Psychophysics, 1973, 14, 365-370.

Klapp. S. Implicit speech inferred from response latencies in same-different decisions. Journal of Experimental Psychology, $1971,91,262-267$.

Klapp, S., Anderson, W. G., \& Berrian, R. W. Implicit speech in reading reconsidered. Journal of Experimental Psychology, $1973,100,368-374$.

Kolers, P. A. Three stages in reading. In $H$. Levin and J. P Williams (Eds.), Basic studies on reading. New York: Basic Books, 1970.

Kolers, P. Experiments in reading. Scientific American, 1973, 227, 84-91

Kolers, P. A., \& Lewis, C. L. Bounding of letter sequences and the integration of visually presented words. Acta Psychologica, 1972, 36, 112-124.

Krueger, L. E. The effect of acoustic confusability on visual search. American Journal of Psychology, 1970, 83, 389-400.

Lackner, J., \& Garrett, M. Resolving ambiguity: Effects of biasing context in the unattended ear. Cognitive Psychology, $1973,1,359-372$.

Landauer, T. K. Rate of implicit speech. Perceptual \& Motor Skills, 1962, 15,646 .

Lashley, K. S. Cerebral organization and behavior. Research Publications, Association for Research in Nervous \& Mental Diseases, $1958,36,1-18$.

Lewis, J. L. Semantic processing of unattended messages using dichotic listening. Journal of Experimental Psychology, 1970. $85,225-228$,

Liberman, A. M., Cooper, F. S., Shankweiler, D. P., \& Studdert-Kennedy, M. Perception of the speech code. Psychological Review, 1967, 74, 392-409.

Mackay, D. G. Aspects of the theory of comprehension, memory and attention. Quarterly Journal of Experimental Psychology, 1973, 25, 22-40.

Mackworth, N. H. Visual noise causes tunnel vision. Psychonomic Science, 1965, 3, 67-68.

Mandler, G., \& Worden, $\mathbf{P}$. Semantic processing without permanent storage. Journal of Experimental Psychology, 1973. 100, 277-283.

Massaro, D. W. Perception of letters, words, and non-words. Joumal of Experimental Psychology, 1973, 100, 349-353.

Massaro, D. W. Perceptual units in speech recognition. Journal or Experimental Psychology, 1974, 102, 199-208.

Mattingly, I. G., Liberman, A. M., Syrdal, A. K. \& Halwes, T. Discrimination in speech and nonspeech modes, Cognitive Psychology, 1971, 2, 131-157.

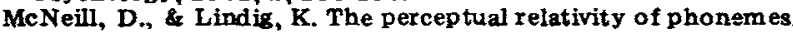
syllables, words and sentences. Journal of Verbal Learning \& Verbal Behavior, $1973,12,419-430$.

Merikle, P. M., Coltheart, M., \& Lowe, D, G. On the selective effects of a patterned masking stimulus. Canadian Journal of Psychology, 1971, 25, 264-279

Meyer, D. E., Schvaneveldt, R. W, \& R uddy, M. G. Functions of graphemic and phonemic codes in visual word recognition. Memory \& Cognition, 1974a, 2, 309-321.

Meyer, D. E., Schvaneveldt, $R$. W., \& Ruddy, M. G. Loci of contextual effects on viaual word recognition. To be publithed in $P$. Rabbitt (Bd.), Attention and performance. Vol. V. New York: Academic Press, $1974 \mathrm{~b}$.

Mezrich, J. J. The word superiority effect in brief vicual displays: Elimination by vocalization. Perception \& Psychophysics, $1973,13,45-48$

Mishkin, M., \& Forgays, D. G. Word recognition as a function of retinal locus. Journal of Experimental Psychology, 1952, 43, 43-48.

Morton, J. A retest of the response-bias explanation of the word fréquency effect. British Journal of Mathematical \& Statistical Psychology, 1968, 21, 21-23.

Morton. J. Interaction of information in word recognition. Psychological R eview, 1969, 76, 165-178.

Neill, D. O., Sampson, H., \& Gribben, J. A. Hemiretinal effects in tachistoscopic letter recognition. Journal of Experimental Psychology, 1971, 91, 129-135.

Neisser, U. Cognitive psychology. New York: Appleton-Century-Crof ts, 1967.

Neisser, U. Selective reading: A method for the study of visual attention. Paper presented at the Symposium on Attention: Some Growing Pains in Recent Research. XIX International Congress of Psychology, London, 1969.
Norman, D. A. Memory and attention. New York: Wiley, 1969

Orbach, J. Retinal locus as a function in the recognition of visually presented words. American Journal of Psychology. $1952,65,555-562$

Orbach, J. Differential recognition of Hebrew and English words in right and left visual fields as a function of cerebral dominance and reading habits. Neuropsychologia, 1967, 5, $127-134$.

Posner, M. I., Boies, S. J., Eichelman, W. H., \& Taylor, R, L. Retention of visual and name codes of single letters. Journal of Experimental Psychology Monograph, 1969, 79(1, Part 2).

Ratliff, F. Machbands: Quantitative studies on neural network in the retina. San Francisco: Holden-Day, 1965.

Reicher, G. M. Perceptual recognition as a function of meaningfulness of stimulus material. Journal of Experim ental Psychology, 1969, 81, 275-280.

Robinson, G. M. The delayed auditory feedback effect is a function of speech rate. Journal of Experimental Psychology, $1972,95,1-5$

Ruberstein, H., Lewis, S. S., \& Rubenstein, M. A. Evidence for phonemic recoding in visual word recognition. Journal of Verbal Learning \& Verbal Behavior, 1971, 10, 645-657.

Rupf, J. A., Hughes, G. W., \& House, A. S. Speech-sy nchronized versus periodic interaural switching of speech. Journal of the Acoustical Society of America, 1971, 49, 608-610.

Savin, H. B., \& Bever, T. G. The nonperceptual reality of the phoneme. Journal of Verbal Learning \& Verbal Behavior. $1970,9,295-302$.

Scheerer, E. Simultane und sukzessive Verarbeitung bei der Identifikation visueller Reizmuster. PhD dissertation. Bochum, 1970.

Schubert, E. D., \& Parker, C. D. Addition to Cherry's findings on switching speech between the two ears. Journal of the Acoustical Society of America, 1954, 27, 792. (L)

Shaw, P., \& Weigel, G. A. Effects of bars and blanks on recognition of words and nonwords embedded in a row of letters. Perception \& Psychophysics, 1973, 14, 117-124.

Smith, E. E., \& Haviland. S. E. Why are words perceived more accurately than nonwords? Journal of Experimental Psy chology, 1972, 92, 59-64.

Smith, F. Understanding reading: A psycholinguistic analysis of reading and learning to read. New York: Holt, Rinehart, \& Winston, 1971.

Somekh, D. E., \& Wilding, J. M. Perception without awareness in a dichoptic viewing situation. British Journal of Psychology, $1973,64,339-349$.

Sperling, G. The information available in brief visual presentation. Psychological Monographs, 1960, 76(Whole No. 11).

Sperling, G. Successive approximations to a model for short-term memory. Acta Psychologica, 1967, 27, 285-292.

Spoehr, K. T., \& Smith, E. E. The role of syllables in perceptual processing. Cognitive Psychology, 1973, 5, 71-89.

Stanners, R. F., \& Forbach, G. B. Analysis of letter strings in word recognition. Journal of Experimental Psychology, 1973, 98, 31-35.

Steinheiser, F. H., \& Burrows, D. J. Chronometric analysis of speech perception. Perception \& Psychophysics, 1973, 13. 426-430.

Thompson, M. C., \& Massaro, D. W. Visual information and redundancy in reading. Journal of Experimental Psychology, $1973,98,49-54$

Townsend, J. J., Taylor, S. G., \& Brown, D. R. Lateral masking for letters with unlimited viewing time. Perception \& Psychophysies, 1971, 10, 375-378.

Travers, J. R. The effects of forced serial processing on identification of words and random letter strings. Cognitive Psychology, 1973, 5, 109-137.

Treisman, A. M. Strategies and models of selective attention. Psychological R eview, 1969, 76, 282-299.

Venezky, R. L. Regularity in reading and spelling. In $H$. Levin and $J$. P. Williams (Eds.), Basic studies on reading. New York: Basic Books, 1970.

Vitz, P. C., \& Winkler, B. S. Predicting the judged "similarity of sound" of English words. Journal of Verbal Learning \& Verbal Behavior, 1973, 12, 373-388

Volkman, F. C., Sehick, A. N. L., \& Riggs, L. A. Time course of visual inhibition during voluntary saccades. Journal of the Optical Society of America, 1968, 58, 562-569.

Warren, R. M. Id entification times for phonemic components of graded complexity and for spelling of speech. Perception \& Psychophysics, 1971, 9, 345-349.

Wheeler, D. D. Processes in word recognition. Cognitive Psychology, 1970, 1, 59-85.

Willows, D. M., \& MacKinnon, G. E. Selective reading: Attention to the "unattended" lines. Canadian Journal of Psychology, 1973, 37, 292-304.

Wise, C. M. Applied phonetics. New York: Prentice Hall, 1957.

(R eceived for publication February 25, 1974; revision received June 28,1974 .) 